\begin{tabular}{ll|l}
\cline { 2 - 3 } & \multicolumn{2}{l}{ Intervent Neurol 2013;2:183-192 } \\
\cline { 2 - 4 } & $\begin{array}{l}\text { DOI: 10.1159/000363068 2014 S. Karger AG, Basel } \\
\text { Published onlIne: June 27, 2014 }\end{array}$ & $\begin{array}{l}\text { (C) } \\
\text { 1664-9737/14/0024-0183 } \$ 39.50 / 0 \\
\text { www.karger.com/ine }\end{array}$ \\
\hline
\end{tabular}

\title{
Review
}

\section{Radiation-Induced Carotid Artery Stenosis: A Comprehensive Review of the Literature}

\author{
Jiaping $\mathrm{Xu}^{\mathrm{a}, \mathrm{b}}$ Yongjun $\mathrm{Cao}{ }^{\mathrm{a}, \mathrm{b}}$ \\ aDepartment of Neurology, The Second Affiliated Hospital of Soochow University, and \\ ${ }^{b}$ Institute of Neuroscience, Soochow University, Suzhou, China
}

\section{Key Words}

Radiotherapy · Carotid stenosis · Pathogenesis - Risk factors · Prevention · Treatment .

Follow-up

\begin{abstract}
In recent decades, with the improvement of radiotherapy (RT) technology and comprehensive treatment, the survival rate of head and neck malignancies has gained remarkable progress. Vascular injury and subsequent carotid stenosis following RT, as the backbone of treatment, have received increasing attention. Many investigations have demonstrated that radiation can result in the increase in carotid intima-media thickness, carotid stenosis and consequently lead to a higher risk of cerebrovascular events such as transient ischemic attack and stroke. In this review, we will examine the incidence of radiation-induced carotid artery stenosis, its morphological and histological characteristics, as well as its pathogenesis. The treatment and prevention methods, including follow-up strategies, will also be discussed at the end of the present review.

(C) 2014 S. Karger AG, Basel
\end{abstract}

\section{Introduction}

In recent decades, with the improvement of radiotherapy (RT) technology and comprehensive treatment, the survival rate of head and neck cancer patients has gained remarkable progress. RT is the mainstay of the comprehensive treatments for malignancies of the head and neck, including breast cancer and lymphoma. In the past, research focused on the microvascular and arterial injury after radiation exposure. However, it is increasingly recognized that large vascular injury is a major sequela of head and neck radiation and is of greater 
clinical significance. The vascular complications caused by RT are generally well known; however, the exact mechanism of radiation-induced carotid artery disease is not clear, although it consists of not only direct and indirect damage, but also accelerated atherosclerosis [1]. The risk factors, follow-up and prevention strategies will be presented here. At the end of this review, we will discuss the characteristics, clinical manifestations, diagnosis and some treatment methods, with reference to the relevant literature and date.

\section{Incidence and Prevalence of RT-Induced Carotid Stenosis}

In the past, the prevalence of carotid stenosis after RT was thought to be low. However, with the improvement of imaging techniques and the increase in the clinicians' awareness, increasing attention has been paid to this area. Lam et al. [2] found that arterial stenosis was more common in the postradiation group than the preradiation group, which consisted of newly diagnosed nasopharyngeal carcinoma patients (56/71 vs. 11/51). The overall prevalence of extracranial artery disease was 56 of 71 (78.9\%), and significant stenosis ( $>50 \%)$ was only found in the postradiation group.

In order to determine the prevalence and risk factors for carotid stenosis after RT, Cheng et al. [3] established a prospective cross-sectional screening of extracranial carotid stenosis by color flow duplex ultrasonography. They found that 27 post-RT patients $(27 / 96,28 \%)$ had internal carotid artery (ICA) stenosis of $30 \%$ or more on either side of the neck, and the stenosis was critical $(\geq 70 \%)$ in 12 patients $(12 / 96,13 \%)$. Nevertheless, there were only 8 patients $(8 / 96,8 \%)$ with moderate ICA stenosis (30-69\%) and none with common carotid artery (CCA) or ICA stenosis of $\geq 70 \%$ or occlusion. Similarly, Huang et al. [4] showed that the intima-media thickness (IMT) of the CCA was significantly increased in nasopharyngeal carcinoma patients after RT compared to the control group. They also found that the IMT, a good indicator of the severity of atherosclerotic disease, increased in a linear manner with duration of RT. The results of another investigation [5] demonstrated an increased risk of stroke in patients aged $<60$ years irradiated for head and neck tumors. This finding was supported by Smith et al. [6] who identified 6,862 patients (mean age: $76 \pm 7$ years) after treatment with RT alone, surgery plus RT or surgery alone. It was shown that the 10-year incidence of cerebrovascular events was $34 \%$ in patients treated with radiation alone compared to $25 \%$ in the surgery plus RT group, and $26 \%$ in the third group $(\mathrm{p}<0.01)$.

From previous results, we can conclude that patients with malignant head and neck tumors after RT harbor a higher risk of carotid stenosis and cerebrovascular events, which consist of transient ischemic attack (TIA) and stroke. This finding indicates that radiation oncologists and neurologists should pay more attention to this aspect.

The differences in the incidence data among these aforementioned findings may result from demographic characteristics, the median follow-up time (interval between RT with ultrasound examination) or some other potential factors. Greater sample sizes and a longer follow-up period are required to determine the precise incidence of radiation-induced carotid stenosis.

\section{Pathogenesis}

The wall of the carotid artery consists of three layers: the intima, the media and the adventitia. The intima lies in the innermost layer and is formed of endothelial cells and internal elastic lamina. The middle layer, the media, is composed of smooth muscle cells (SMCs). The outermost layer, the adventitia, contains connective tissue, fibroblasts and SMCs. 


\section{Endothelium Dysfunction}

The exact pathogenesis of radiation-induced carotid artery disease is still unclear. The primary mechanism may be a dysfunction of the endothelial cells, which are highly sensitive to the radiation exposure [7].

The damaged endothelial cells do not function as a barrier against plasma lipoproteins; subsequently, the lipid filtration causes the activation of the lysosomal system and the proliferation of the endothelial cells [8].

Sugihara et al. [9] found that in carotid arteries undergoing radiation, endotheliumdependent relaxation mediated by nitric oxide and prostacyclin was specifically impaired. Nevertheless, a significant morphological damage of the endothelium was not observed. One possible explanation for this phenomenon is that the decline of the endothelium function appears earlier than the morphological changes. The impaired nitric oxide-dependent relaxation was attributed to the lack of endothelial nitric oxide synthase expression, which indicated the drop of the endothelial cells' function [9].

The extensive endothelial damage was the initial process with nuclear disruption, platelet aggregation and fibrin deposition [10] followed by the destruction of the internal elastic lamina and marked thickening of the endothelium. The large arteries will become stiffer and less elastic with the extensive fibrosis of the vessel wall, and consequently, diastolic dysfunction will descend. The intimal proliferation of mainly fibrous tissue and marked thickening of the endothelium leads to luminal narrowing [11].

Another proposed mechanism of inflammatory vascular damage after radiation in humans is via the activation of nuclear factor-kappa B [12]. Oxidative stress and inflammation may also be involved in the development of radiation-induced carotid stenosis, a late complication of RT [13].

Exposure to ionizing radiation leads to the increase in reactive oxygen species and free radicals. Subsequently, DNA damage and lipid and protein oxidation occur when these free radical insults are beyond the cellular repair and scavenger systems.

Inflammatory changes appear early during RT and may be reflected in the elevated inflammatory biomarkers. The appearance of inflammatory biomarkers in the early stage may be useful in evaluating the progress of carotid stenosis after RT, but this requires further prospective investigations [14].

\section{Injury and Occlusion of the Vasa Vasorum}

The vasa vasorum is a kind of microvasculature network that is especially vulnerable to radiation damage [7]. Occlusion of the vasa vasorum also plays an important role in the progression of the ischemic necrosis, resulting in fibrosis of the adventitia, destruction of the internal elastic lamina and remarkable thickening of the endothelium. It is possible that the IMT is a combined result of both fibrin accumulation in the medial and intimal layers and their gradual replacement with collagen [15].

\section{Accelerated Atherosclerosis}

The last mechanism of radiation-induced carotid stenosis is accelerated atherosclerosis. Cheng et al. [3] showed that age was a significant risk factor for severe post-RT carotid stenosis. Moreover, they suggested that a mechanism of accelerated atherosclerosis may augment the initial injury. The increase in carotid IMT (CIMT) seen in irradiated carotid arteries also suggested the potential mechanism, indicating that radiation may accelerate the progression of atherosclerosis [16].

Dorresteijn et al. [11] found that RT was an independent risk factor for vascular disease, like other more common factors, particularly in those patients with a post-RT interval $>10$ years.

However, we tend to consider that radiation-induced carotid stenosis results from the combined effects of radiation injury and the traditional risk factors, such as hypertension, 
diabetes, hyperlipidemia, smoking, and obesity, especially in older patients. This highlights that more attention should be placed on the comprehensive modification of the risk factors for atherosclerosis in patients with a history of RT.

\section{Risk Factors}

In order to identify the risk factors for carotid stenosis undergoing RT, a number of investigations were carried out. The interval between RT and onset of the cerebrovascular symptoms is accepted to be a considerable risk factor.

Dorresteijn et al. [11] examined the difference in CIMT among 42 unilaterally irradiated parotid tumor patients by performing B-mode ultrasonography. It was demonstrated that RT is an independent risk factor for vascular disease, particularly after a post-RT interval $>10$ years. The same group also found that hypertension and diabetes mellitus played an important role in increasing the risk of stroke after RT [5].

It was also revealed that patients who had neck irradiation $>5$ years prior have an eight times higher risk of developing carotid stenosis compared to those with a post-RT time interval $<60$ months ( $p<0.001$ ) [17]. Lam et al. [2] found that age and irradiation were important factors in the development of carotid stenosis. Chang et al. [18] showed a positive correlation between the total plaque score, which is an index of atherosclerosis, RT use, RT dose, length of time after RT, hyperlipidemia, and age. The study of Cheng et al. [3] revealed that severe post-RT carotid stenosis was associated with age, smoking, heart disease, no prior oncological surgery, cerebrovascular symptoms and interval from RT. The risk of radiation-induced carotid stenosis seems to depend on the site of primary malignancy and the radiation doses.

Cheng et al. [17] also discovered that patients with nasopharyngeal carcinoma, laryngocarcinoma and hypopharyngeal carcinoma had a six times higher risk of developing carotid stenosis than those suffering from other tumors. A possible explanation for the higher risk may be the differences in radiation doses, which were confirmed by Chang et al. [18]. In conclusion, RT in addition to other traditional risk factors has a combined effect on the progression of postradiation atherosclerosis.

\section{Follow-Up and Prevention Strategies}

The high prevalence of carotid stenosis after RT for head and neck tumors is of great clinical significance. All patients with prior cervical RT, with or without traditional risk factors, should be observed. Nevertheless, there is no consensus on the frequency of screening and the time of follow-up start.

Halak et al. [19] recommended that follow-up should include yearly duplex scanning, beginning 3 years after completion of RT. Nevertheless, Cheng et al. [3] recommended routine screening in patients who have received RT to the neck for $>5$ year because those patients had a 15 times higher chance of developing carotid stenosis. A series of investigations are needed to determine the accurate onset time of the screening.

Examination of a wider range of the carotid artery, including the distal edge of the ICA, in patients after RT is recommended [20]. Patients with traditional risk factors, such as hypertension, smoking, and hyperlipidemia, may harbor a higher risk of cerebrovascular events; therefore, aggressive risk factor modifications should be applied in an attempt to delay the progression of carotid stenosis after RT.

Follow-up strategies should include questionnaires about symptoms of cerebral ischemia, noninvasive imaging screening and routine bruit auscultation [21]. 
Consequently, ultrasound examination of patients at high risk of carotid stenosis and cerebrovascular events is essential for the early detection and possible interventions of late radiation-induced complications [2]. Steele et al. [1] recommended that patients should receive aggressive screening before and after RT; this may be useful to identify the high-risk population. Patients should be informed of the higher risk to develop carotid stenosis and cerebrovascular events after RT. They should also be invited to adopt a stricter compliance with the measures to eliminate the controllable risk factors. Once the patients present cerebrovascular ischemic symptoms, such as TIA, syncope, amaurosis fugax or stroke, the physicians should be aware of the relationship between carotid stenosis and the emerging symptoms, find out the underlying reasons and take further interventions.

However, it is of great significance to maintain the balance between the risk of developing carotid stenosis and the benefits of RT for the treatment of head and neck malignancies [22, 23]. RT should be carried out in order to enhance treatment effectiveness and protect the adjacent normal tissues. Newer and advanced RT techniques, such as more conformal RT, image-guided RT [24], hyperfractionated radiation [25], stereotactic RT, brachytherapy or radioprotective agents, could potentially decrease cerebrovascular morbidity and mortality.

\section{Characteristics of Radiation-Induced Carotid Artery Stenosis}

Clinically, RT patients are relatively younger and have a lower incidence of other atherosclerosis risk factors compared to non-RT patients. Therefore, some scholars regard the lesions in previously irradiated patients as a clinically distinct entity compared to traditional atherosclerotic stenosis $[16,26]$.

Stenotic lesions after RT tend to be longer, and the maximal stenosis of radiation-induced lesions is inclined to distribute at the end of the stenotic area, including in the proximal CCA [20]. However, in the control group, the maximal stenotic sites were observed almost around the center of the stenotic lesion. Similar findings were shown in the investigation of Lam et al. [2], in which they observed that CCA or ICA were most commonly involved (55 of 71 vs. 11 of 51; $\mathrm{p}<0.01$ ), followed by the external carotid artery ( 32 of 71 vs. 1 of $51 ; p<0.01$ ) and vertebral artery ( 5 of 71 vs. $0 ; p=0.069$ ). However, the most common sites of traditional atherosclerotic carotid stenosis are carotid bifurcation [27] and the proximal segment of ICA.

Concerning the sonographic features, some differences were identified [27]. Plaques exposed to radiation are more diffuse in appearance, less shadowing, and more hypoechoic. Currently, anechoic or hypoechoic plaques are believed to be related to intraplaque hemorrhage or lipid deposits within the plaque and are associated with an increased risk of stroke. Furthermore, vessel damage after RT extends beyond the margins of the radiation field, often to the proximal common carotid and distal ICA [28] which are relatively more difficult to be detected by the traditional ultrasound techniques.

Fokkema et al. [29] found that plaques after RT had less infiltration of macrophages and smaller lipid core which suggested that RT plaques were more stable and less active compared to nonradiated atherosclerotic lesions. These findings are consistent with the fact that radiated arteries are more prone to develop restenosis than those without radiation [30].

\section{Clinical Manifestations}

Several studies have demonstrated that RT can induce and accelerate the increase in the IMT of the narrow carotid arteries. The increase in the IMT and narrowing of the vascular lumen of carotid arteries will decrease the blood flow to the corresponding cerebrovascular 
areas and result in the relevant symptoms, which are always subtle and therefore undetected in most patients [22].

The interval from irradiation to symptomatic vascular diseases ranges from several months to two decades, and it seems to be closely related to the diameter of the irradiated arteries [7]. The typical manifestations of extracranial carotid stenosis include amaurosis fugax, paresis, sensory disturbances, aphasia, and dysarthria. On the other hand, dizziness, diplopia, amnesia, and headache are relatively atypical [31]. The carotid bruit may be heard during the physical examination.

Cognitive decline, caused by the injury of the temporal lobe, is also a significant but largely unrecognized sequela following irradiation for head and neck tumors, particularly cancer of the nasopharynx and paranasal sinuses [32].

The patients should be educated to recognize the relevant symptoms and report the emerging symptoms to the physicians. In addition, the physicians ought to be aware of the relationship between the new onset manifestations and the carotid stenosis after RT.

\section{Diagnosis}

\section{Carotid Ultrasound Techniques}

The diagnosis of carotid stenosis still relies principally on the imaging approaches. CIMT, which can be measured relatively easily and noninvasively by Doppler ultrasonography, is a good indicator of atherosclerotic disease and a significant predictor of future vascular events [33]. The increase in the CIMT is also one of the earliest visible features that can be observed in the first 2 years after RT [34].

For an absolute CIMT difference of $0.1 \mathrm{~mm}$, the stroke risk increases by 13-18\% [35]. In addition, the IMT increased linearly with duration of RT [4]. Furthermore, elderly patients with increased CIMT and without a history of cardiovascular disease are directly associated with a remarkably higher risk of myocardial infarction and stroke [33]. Emerging new techniques, such as ultrasonographic 2D-strain imaging [36], to measure arterial stiffness and contrast ultrasound imaging [37] may be more effective in the detection of early atherosclerotic vascular changes.

\section{Neck Auscultation}

Auscultation for carotid bruits remains worthwhile in the general population because the presence of a bruit means that there is a one-in-four chance of having significant carotid stenosis [38].

However, because of its low sensitivity and positive predictive value, carotid artery ultrasound is needed when a carotid bruit is heard during the physical examination [38].

The presence of a carotid bruit has significant prognostic implications. Patients with a carotid bruit have a $>4$ times higher risk of TIA, twice the risk of stroke, and an increased risk of death from stroke when compared to controls without carotid bruits [39].

\section{Computed Tomography Angiography, Magnetic Resonance Imaging and Digital}

\section{Subtraction Angiography}

Conventional digital subtraction angiography remains the golden standard for the diagnosis of carotid arterial stenosis. Magnetic resonance imaging and computed tomography angiography are also widely utilized in the diagnosis of carotid stenosis.

Yet, in our view, Doppler duplex ultrasound and auscultation should be applied as the routine diagnostic methods during screening and follow-up. Those patients with suspicious significant stenosis can be substantiated by magnetic resonance imaging, computed tomography angiography or even by digital subtraction angiography. 


\section{Treatment}

Symptomatic patients or those with severe carotid stenosis may require carotid endarterectomy (CEA) or carotid angioplasty and stenting (CAS) [40].

Both CAS and CEA are the two major alternative treatment methods with a low risk of cerebrovascular events. Patients undergoing CEA had more temporary cranial nerve injury (CNI), and CAS patients had a higher rate of late cerebrovascular events and restenosis, even though they mostly remained asymptomatic.

\section{Carotid Endarterectomy}

Even though the standard treatment for extracranial artery stenosis is CEA, higher rates of CNI and wound complications including infection limit CEA applications in patients with prior radiation.

The adhesion of different layers of the vessel wall [41], as well as the extensive stenosis and more diffuse plaques [20], resulting from the prior irradiation, add to the difficulty of eliminating the plaques [42]. The complications of endarterectomy also augment because of the incidence of adhesions or scar tissue after a preceding radical neck dissection.

Tallarita et al. [43] showed that open surgery patients with prior radical neck dissections had more wound complications (14 vs. 5\%) and more CNIs (28 vs. 9\%) compared to those without prior neck dissections. Previous tracheotomy due to initial malignancy also increases the chances of infection. Therefore, endarterectomy may not be the best choice of treatment for these particular patients.

\section{Carotid Angioplasty and Stenting}

CAS should be considered as an alternative to CEA for those patients with high surgical risk [31]. No CNI or wound complications in patients with a history of RT are the main advantages of CAS [44]. Over the past few decades, CAS has been increasingly used and is gaining more and more popularity after RT.

The extensive disease presents a potentially larger surface area for embolization, which leads to a higher risk of cerebrovascular events. Long-segment angioplasty and placement of longer or additional stents predisposes to intimal hyperplasia and promotes a higher recurrence rate [42].

The underlying mechanism leading to in-stent restenosis is explained by myointimal hyperplasia with SMC proliferation [30]. However, most in-stent restenosis remained asymptomatic.

In a recent investigation, Huang et al. [45] have found that the primary outcomes, comprising all-cause mortality, any ipsilateral recurrent TIA or stroke, and major adverse cerebrovascular events, did not show a significant difference between the two groups during the 5 years of follow-up. However, more asymptomatic carotid restenosis was found in the RT group.

In spite of the high risk of restenosis, cutting balloon angioplasty has emerged as an excellent treatment strategy for in-stent stenosis [44]. The higher risk of stroke caused by embolization may be preferably resolved by the use of the cerebral protection devices.

With the further development of new stent devices, delivery techniques, and cerebral protection devices, the use of CAS for the treatment of radiation-induced carotid stenosis will become safer and more durable [46].

\section{Medication}

The effect of antiplatelet agents, anticoagulant, antihypertension or lipid-lowering therapy is still unclear. Antiplatelet agents and statins may be effective for preventing the 
progression of radiation-induced carotid stenosis [47]. Favre et al. [48] found that the incidence of anatomic events decreased significantly by using statins in the CAS group. A large number of prospective investigations are needed to identify the effects of a medication therapy in prevention and treatment.

\section{Conclusion}

Irradiation on the carotid area is a significant risk factor of developing carotid stenosis and subsequently cerebrovascular events. It has a great impact on the quality of life of survivors of head and neck malignancies. Long-term surveillance with carotid ultrasound techniques and aggressive modification of the traditional risk factors is cost-effective. CAS may be a preferable treatment method for symptomatic patients or those with severe carotid stenosis. However, more prospective investigations are needed to determine the pathogenesis, prevention and early detection methods.

\section{References}

1 Steele SR, Martin MJ, Mullenix PS, Crawford JV, Cuadrado DS, Andersen CA: Focused high-risk population screening for carotid arterial stenosis after radiation therapy for head and neck cancer. Am J Surg 2004;5: 594-598.

2 Lam WW, Leung SF, So NM, Wong KS, Liu KH, Ku PK, Yuen HY, Metreweli C: Incidence of carotid stenosis in nasopharyngeal carcinoma patients after radiotherapy. Cancer 2001;92:2357-2363.

-3 Cheng SW, Ting AC, Lam LK, Wei WI: Carotid stenosis after radiotherapy for nasopharyngeal carcinoma. Arch Otolaryngol Head Neck Surg 2000;126:517-521.

-4 Huang TL, Hsu HC, Chen HC, Lin HC, Chien CY, Fang FM, Huang CC, Chang HW, Chang WN, Huang CR, et al: Long-term effects on carotid intima-media thickness after radiotherapy in patients with nasopharyngeal carcinoma. Radiat Oncol 2013;8:261.

5 Dorresteijn LD, Kappelle AC, Boogerd W, Klokman WJ, Balm AJ, Keus RB, van Leeuwen FE, Bartelink H: Increased risk of ischemic stroke after radiotherapy on the neck in patients younger than 60 years. J Clin Oncol 2002;20:282-288.

6 Smith GL, Smith BD, Buchholz TA, Giordano SH, Garden AS, Woodward WA, Krumholz HM, Weber RS, Ang KK, Rosenthal DI: Cerebrovascular disease risk in older head and neck cancer patients after radiotherapy. J Clin Oncol 2008;26:5119-5125.

7 Murros KE, Toole JF: The effect of radiation on carotid arteries. A review article. Arch Neurol 1989;46:449455.

8 Konings AW, Hardonk MJ, Wieringa RA, Lamberts HB: Initial events in radiation-induced atheromatosis I. Activation of lysosomal enzymes. Strahlentherapie 1975;150:444-448.

-9 Sugihara T, Hattori Y, Yamamoto Y, Qi F, Ichikawa R, Sato A, Liu MY, Abe K, Kanno M: Preferential impairment of nitric oxide-mediated endothelium-dependent relaxation in human cervical arteries after irradiation. Circulation 1999;100:635-641.

10 Fonkalsrud EW, Sanchez M, Zerubavel R, Mahoney A: Serial changes in arterial structure following radiation therapy. Surg Gynecol Obstet 1977;145:395-400.

11 Dorresteijn LD, Kappelle AC, Scholz NM, Munneke M, Scholma JT, Balm AJ, Bartelink H, Boogerd W: Increased carotid wall thickening after radiotherapy on the neck. Eur J Cancer 2005;41:1026-1030.

\$2 Halle M, Gabrielsen A, Paulsson-Berne G, Gahm C, Agardh HE, Farnebo F, Tornvall P: Sustained inflammation due to nuclear factor-kappa B activation in irradiated human arteries. J Am Coll Cardiol 2010;55:1227-1236.

13 Zhao W, Robbins ME: Inflammation and chronic oxidative stress in radiation-induced late normal tissue injury: therapeutic implications. Curr Med Chem 2009;16:130-143.

14 Gujral DM, Shah BN, Chahal NS, Senior R, Harrington KJ, Nutting CM: Clinical features of radiation-induced carotid atherosclerosis. Clin Oncol (R Coll Radiol) 2014;26:94-102.

15 Cheng SW, Ting AC, Wu LL: Ultrasonic analysis of plaque characteristics and intimal-medial thickness in radiation-induced atherosclerotic carotid arteries. Eur J Vasc Endovasc Surg 2002;24:499-504.

16 Gujral DM, Chahal N, Senior R, Harrington KJ, Nutting CM: Radiation-induced carotid artery atherosclerosis. Radiother Oncol 2014;110:31-38.

17 Cheng SW, Wu LL, Ting AC, Lau H, Lam LK, Wei WI: Irradiation-induced extracranial carotid stenosis in patients with head and neck malignancies. Am J Surg 1999;178:323-328. 
18 Chang YJ, Chang TC, Lee TH, Ryu SJ: Predictors of carotid artery stenosis after radiotherapy for head and neck cancers. J Vasc Surg 2009;50:280-285.

19 Halak M, Fajer S, Ben-Meir H, Loberman Z, Weller B, Karmeli R: Neck irradiation: a risk factor for occlusive carotid artery disease. Eur J Vasc Endovasc Surg 2002;23:299-302.

20 Shichita T, Ogata T, Yasaka M, Yasumori K, Inoue T, Ibayashi S, Iida M, Okada Y: Angiographic characteristics of radiation-induced carotid arterial stenosis. Angiology 2009;60:276-282.

-21 Lam WW, Yuen HY, Wong KS, Leung SF, Liu KH, Metreweli C: Clinically underdetected asymptomatic and symptomatic carotid stenosis as a late complication of radiotherapy in Chinese nasopharyngeal carcinoma patients. Head Neck 2001;23:780-784.

22 Abayomi OK: Neck irradiation, carotid injury and its consequences. Oral Oncol 2004;40:872-878.

23 Scott AS, Parr LA, Johnstone PA: Risk of cerebrovascular events after neck and supraclavicular radiotherapy: a systematic review. Radiother Oncol 2009;90:163-165.

24 Sterzing F, Engenhart-Cabillic R, Flentje M, Debus J: Image-guided radiotherapy: a new dimension in radiation oncology. Dtsch Arztebl Int 2011;108:274-280.

25 Bourhis J, Overgaard J, Audry H, Ang KK, Saunders M, Bernier J, Horiot JC, Le Maître A, Pajak TF, Poulsen MG, O’Sullivan B, Dobrowsky W, Hliniak A, Skladowski K, Hay JH, Pinto LH, Fallai C, Fu KK, Sylvester R, Pignon JP: Hyperfractionated or accelerated radiotherapy in head and neck cancer: a meta-analysis. Lancet 2006;368: 843-854.

-26 Fokkema M, den Hartog AG, van Lammeren GW, Bots ML, Pasterkamp G, Vink A, Moll FL, de Borst GJ: Radiation-induced carotid stenotic lesions have a more stable phenotype than de novo atherosclerotic plaques. Eur J Vasc Endovasc Surg 2012;43:643-648.

-27 Lam WW, Liu KH, Leung SF, Wong KS, So NM, Yuen HY, Metreweli C: Sonographic characterisation of radiationinduced carotid artery stenosis. Cerebrovasc Dis 2002;13:168-173.

-28 Rockman CB, Riles TS, Fisher FS, Adelman MA, Lamparello PJ: The surgical management of carotid artery stenosis in patients with previous neck irradiation. Am J Surg 1996;172:191-195.

29 Fokkema M, den Hartog AG, van Lammeren GW, Bots ML, Pasterkamp G, Vink A, Moll FL, de Borst GJ: Radiation-induced carotid stenotic lesions have a more stable phenotype than de novo atherosclerotic plaques. Eur J Vasc Endovasc Surg 2012;43:643-648.

-30 Fokkema M, den Hartog AG, Bots ML, van der Tweel I, Moll FL, de Borst GJ: Stenting versus surgery in patients with carotid stenosis after previous cervical radiation therapy: systematic review and meta-analysis. Stroke 2012;43:793-801.

-31 Eckstein HH, Kühnl A, Dörfler A, Kopp IB, Lawall H, Ringleb PA: The diagnosis, treatment and follow-up of extracranial carotid stenosis: a multidisciplinary German-Austrian guideline based on evidence and consensus. Dtsch Arztebl Int 2013;110:468-476.

-32 Abayomi OK: Pathogenesis of cognitive decline following therapeutic irradiation for head and neck tumors. Acta Oncol 2002;41:346-351.

-33 O'Leary DH, Polak JF, Kronmal RA, Manolio TA, Burke GL, Wolfson SK Jr: Carotid-artery intima and media thickness as a risk factor for myocardial infarction and stroke in older adults. Cardiovascular Health Study Collaborative Research Group. N Engl J Med 1999;340:14-22.

-34 Muzaffar K, Collins SL, Labropoulos N, Baker WH: A prospective study of the effects of irradiation on the carotid artery. Laryngoscope 2000;110:1811-1814.

35 Lorenz MW, Markus HS, Bots ML, Rosvall M, Sitzer M: Prediction of clinical cardiovascular events with carotid intima-media thickness: a systematic review and meta-analysis. Circulation 2007;115:459-467.

-36 Bjällmark A, Lind B, Peolsson M, Shahgaldi K, Brodin LA, Nowak J: Ultrasonographic strain imaging is superior to conventional non-invasive measures of vascular stiffness in the detection of age-dependent differences in the mechanical properties of the common carotid artery. Eur J Echocardiogr 2010;11:630-636.

37 Feinstein SB: Contrast ultrasound imaging of the carotid artery vasa vasorum and atherosclerotic plaque neovascularization. J Am Coll Cardiol 2006;48:236-243.

-38 Ratchford EV, Jin Z, Di Tullio MR, Salameh MJ, Homma S, Gan R, Boden-Albala B, Sacco RL, Rundek T: Carotid bruit for detection of hemodynamically significant carotid stenosis: the Northern Manhattan Study. Neurol Res 2009;31:748-752.

39 Pickett CA, Jackson JL, Hemann BA, Atwood JE: Carotid bruits and cerebrovascular disease risk: a metaanalysis. Stroke 2010;41:2295-2302.

40 Kashyap VS, Moore WS, Quinones-Baldrich WJ: Carotid artery repair for radiation-associated atherosclerosis is a safe and durable procedure. J Vasc Surg 1999;29:90-96.

-41 Houdart E, Mounayer C, Chapot R, Saint-Maurice JP, Merland JJ: Carotid stenting for radiation-induced stenoses: a report of 7 cases. Stroke 2001;32:118-121.

-42 Ting AC, Cheng SW, Yeung KM, Cheng PW, Lui WM, Ho P, Tso WK: Carotid stenting for radiation-induced extracranial carotid artery occlusive disease: efficacy and midterm outcomes. J Endovasc Ther 2004;11: 53-59.

43 Tallarita T, Oderich GS, Lanzino G, Cloft H, Kallmes D, Bower TC, Duncan AA, Gloviczki P: Outcomes of carotid artery stenting versus historical surgical controls for radiation-induced carotid stenosis. J Vasc Surg 2011;53: 629-636.

44 Tamberella MR, Yadav JS, Bajzer CT, Bhatt DL, Abou-Chebl A: Cutting balloon angioplasty to treat carotid in-stent restenosis. J Invasive Cardiol 2004;16:133-135. 
$\mathrm{Xu}$ and Cao: Radiation-Induced Carotid Artery Stenosis: A Comprehensive Review of the Literature

45 Huang MP, Fang HY, Chen CY, Tan TY, Kuo YL, Hsieh IC, Yip HK, Wu CJ: Long-term outcomes of carotid artery stenting for radiation-associated stenosis. Biomed J 2013;36:144-149.

-46 Ecker RD, Donovan MT, Hopkins LN: Endovascular management of carotid artery disease after radiation therapy and radical neck dissection. Neurosurg Focus 2005;18:e8.

47 Gaugler MH, Vereycken-Holler V, Squiban C, Vandamme M, Vozenin-Brotons MC, Benderitter M: Pravastatin limits endothelial activation after irradiation and decreases the resulting inflammatory and thrombotic responses. Radiat Res 2005;163:479-487.

48 Favre JP, Nourissat A, Duprey A, Nourissat G, Albertini JN, Becquemin JP: Endovascular treatment for carotid artery stenosis after neck irradiation. J Vasc Surg 2008;48:852-858. 